\title{
Coronary Computed Tomography Angiography in Diagnosing Obstructive Coronary Artery Disease in Patients with Advanced Chronic Kidney Disease: A Systematic Review and Meta-Analysis
}

\author{
Xingxing S. Cheng ${ }^{a}$ Suman Mohanty ${ }^{a}$ Valery Turner ${ }^{b}$ \\ Domenico Mastrodicasa $^{b}$ Simon Winther ${ }^{c}$ Dominik Fleischmann ${ }^{b}$ \\ Jane C. Tan ${ }^{a}$ William F. Fearon ${ }^{d}$ \\ a'Division of Nephrology, Department of Medicine, Stanford University School of Medicine, Palo Alto, CA, USA; \\ ${ }^{b}$ Department of Radiology, Stanford University School of Medicine, Palo Alto, CA, USA; 'Department of Cardiology, \\ Regional Hospital Unit West, Herning, Denmark; ${ }^{\mathrm{d}}$ Division of Cardiology, Department of Medicine, Stanford \\ University School of Medicine, Palo Alto, CA, USA
}

\section{Keywords}

Coronary artery disease $\cdot$ Ischemic heart disease .

Diagnostic performance $\cdot$ Coronary computed tomography angiography · Systematic review · Meta-analysis · Chronic kidney disease

\footnotetext{
Abstract

Introduction: Coronary computed tomography angiography (CCTA) is emerging as an important noninvasive testing modality for coronary angiography. The performance characteristic of CCTA in patients with advanced kidney disease is unknown. Methods: We performed a systematic review and meta-analysis of studies specifically investigating the sensitivity and specificity of CCTA compared to coronary angiogram as a reference standard in patients with advanced kidney disease, defined as dialysis dependence or nearing kidney transplantation. Two independent investigators assessed studies for inclusion/exclusion, quality, and characteristics, while a third investigator adjudicated. Results: We identified 4 studies including a total of 217 patients, of whom
}

karger@karger.com www.karger.com/crm

Karger $\stackrel{\text { ! }}{\div}$

GOPEN ACCESS
(C) 2020 The Author(s)

Published by S. Karger AG, Basel

This is an Open Access article licensed under the Creative Commons Attribution-NonCommercial-4.0 International License (CC BY-NC) (http://www.karger.com/Services/OpenAccessLicense), applicable to the online version of the article only. Usage and distribution for commercial purposes requires written permission.
159 were dialysis dependent. Three of the 4 studies had a high risk of bias in patient selection and study flow, while 1 study rated low in all areas of bias. The studies were heterogeneous in their patient selection and CCTA protocol but consistent in their definition of obstructive coronary artery disease. The pooled sensitivity and specificity for CCTA were $0.96(0.87-0.99)$ and $0.66(0.57-0.74)$, respectively. When we restricted the analysis to dialysis-dependent patients, the pooled sensitivity and specificity for CCTA were 0.99 (0.74$1.00)$ and 0.67 (0.49-0.82), respectively. Conclusions: Based on limited data, CCTA appears to have comparable sensitivity but lower specificity relative to the non-kidney disease population.

(C) 2020 The Author(s)

Published by S. Karger AG, Basel

\section{Introduction}

Coronary computed tomography angiography (CCTA) is a noninvasive diagnostic test for obstructive coronary artery disease (CAD). Professional society 
guidelines, such as the American College of Cardiology (ACC)/American Heart Association (AHA) and the European Society of Cardiology guidelines, have accepted CCTA as a first-line diagnostic test in evaluating low-intermediate risk acute chest pain and stable chronic chest pain $[1,2]$. In the general population, the sensitivity and specificity of CCTA in diagnosing $\geq 50 \%$ stenosis ranges are $81-99 \%$ and $64-93 \%$, respectively $[3,4]$. However, the value of CCTA in patients with chronic kidney disease (CKD), pre-dialysis or dialysis-dependent, is less certain. Concerns exist over contrast-induced nephropathy, which resulted in the exclusion of patients with CKD from almost all CCTA studies. Furthermore, coronary artery calcium, an important part of CCTA prognostication in patients without CKD, is elevated to pathologic levels in up to $83 \%$ of patients with dialysis-dependent CKD [5]. Extensive coronary artery calcification in this setting is not always correlated with significant stenosis [6]. The presence of densely calcified plaques also worsens coronary lumen visualization and may lead to an overestimation of luminal stenosis [7]. The diagnostic accuracy of CCTA in identifying obstructive CAD in patients with $\mathrm{CKD}$, therefore, remains unclear.

At the same time, the CKD population is sorely in need of a better noninvasive diagnostic test for obstructive CAD. Cardiovascular mortality, including CAD related, is the greatest cause of mortality in patients with CKD [8]. Kidney transplant, the preferred treatment of dialysis-dependent CKD, usually entails at least one, and possibly multiple, cardiac ischemia tests for "preoperative clearance" [9]. In a 2011 Cochrane meta-analysis of noninvasive cardiac ischemia tests for transplant clearance [10], dobutamine stress echocardiography has the best diagnostic performance of existing noninvasive methods, with a pooled sensitivity and specificity of 0.78 and 0.88 , respectively. At the time of that meta-analysis, there were no data on the performance of CCTA in this population.

Almost a decade has elapsed since the 2011 Cochrane meta-analysis. The purpose of this systematic review and meta-analysis is to review and summarize existing literature on the diagnostic performance of CCTA in patients with advanced CKD. Given the challenge of defining kidney disease and concern of contrast-induced nephropathy in patients with CKD (whom contrast may "tip over" into dialysis dependence), we focused our attention on patients with advanced CKD, i.e., those on approaching dialysis or who are being considered for kidney transplantation.

\section{Methods}

\section{Search Strategy}

In accordance with the PRISMA guidelines [11], we prospectively registered our trial on PROSPERO (registration ID: CRD42019147357). We conducted a computerized search of the PubMed and the Embase databases using specific search terms containing all possible variations of terms for the study modality and patient population (online suppl. S1; for all online suppl. material, see www.karger.com/doi/10.1159/000510402). Two authors (S.M. and V.T.) independently reviewed the title and abstract of all studies resulting from the search. The primary author (X.S.C.) verified all data and resolved any discrepancies.

\section{Study Selection}

We included studies meeting all of the following criteria:

1. conducted in human patients;

2. included patients who had advanced CKD or end-stage kidney disease, defined as dialysis-dependent or undergoing evaluation for a kidney transplant;

3. investigated CCTA for the diagnosis of obstructive CAD;

4. compared CCTA results to concurrent invasive coronary angiography results (gold standard) in the same patient.

We did not exclude pediatric studies (none were found) or studies in language other than English (none were found). We excluded case reports or case series and replies to study authors. Where multiple studies resulted from the same patient group, we carefully reviewed all studies to ensure that each cohort is only included once in our paper.

\section{Data Collection and Quality Assessment}

Two authors (S.M. and V.T.) independently assessed the quality of all papers included in this review using QUADAS-2: A Revised Tool for the Quality Assessment of Diagnostic Accuracy Studies [12]. Briefly, we tailored the tool's questions to our study, removing and adding questions as needed. The questions regarding risk of bias and applicability concerns fell into 4 domains: patient selection, index test, reference test, and flow and timing. We answered questions with yes (low concerns for applicability or low risk of bias), unclear, and no (high concerns for applicability or high risk of bias). The primary author, X.S.C., verified all data and resolved all discrepancies.

Our primary outcomes were the sensitivity and specificity of CCTA in diagnosing obstructive CAD, using coronary angiogram as a reference standard. In data extraction, we collected pertinent data on study design, study population, index test quality, study protocol, and study definition of obstructive CAD, presented in Table 1 and online supplement S2. To complete a secondary analysis restricted to dialysis-dependent patients only, the corresponding author of Winther et al. [13] (S.W.) shared results from the dialysis-dependent subgroup which we included in the analysis.

\section{Statistical Analysis}

We presented categorical and continuous variables from individual studies as frequency (\%) and mean \pm standard deviation, respectively. We reported measures of diagnostic accuracy as point estimates with $95 \%$ confidence intervals in parentheses. To assess heterogeneity, we calculated the Spearman correlation coefficient between the sensitivity and specificity of included trials [14]. Due to the small number of included studies, we were not able to per- 
Table 1. Patient characteristics of included studies

\begin{tabular}{|c|c|c|c|c|c|c|c|}
\hline $\begin{array}{l}\text { First author [ref.], } \\
\text { year }\end{array}$ & Time range & Country & Design & $\begin{array}{l}\text { Subjects, } \\
n\end{array}$ & $\begin{array}{l}\text { Testing } \\
\text { indication }\end{array}$ & $\begin{array}{l}\text { CAD } \\
\text { prevalence, } \%\end{array}$ & $\begin{array}{l}\text { Definition of kidney } \\
\text { disease }\end{array}$ \\
\hline Iio [19], 2008 & $2005-2016$ & Japan & Pros & 19 & Research & 45 & $\begin{array}{l}\text { Diabetic kidney } \\
\text { disease, starting } \\
\text { dialysis }\end{array}$ \\
\hline Park [20], 2011 & $2008-2010$ & Korea & Pros & 29 & $\begin{array}{l}\text { Symptom } \\
\text { or Tx } \\
\text { evaluation }\end{array}$ & 48 & $\begin{array}{l}\text { Dialysis } \\
\text { dependence }\end{array}$ \\
\hline Jug [21], 2013 & $2006-2010$ & US & $\begin{array}{l}\text { Pros and } \\
\text { Retro** }\end{array}$ & 31 & $\begin{array}{l}\text { Symptom } \\
\text { or Tx } \\
\text { evaluation }\end{array}$ & 71 & $\begin{array}{l}\text { End-stage } \\
\text { kidney disease }\end{array}$ \\
\hline Winther [13], 2015 & 2011-2014 & Denmark & Pros & 138 & $\begin{array}{l}\text { Tx } \\
\text { evaluation }\end{array}$ & 22 & $\begin{array}{l}\text { Needs kidney } \\
\text { transplant }\end{array}$ \\
\hline
\end{tabular}

We displayed all prevalences, true positive, false positive, false negative, true negative, and sensitivities and specificities at the patient level, except for Iio et al. [19], in which only vessel-level results were reported. Pros, prospective; Retro, retrospective; Tx, transplant; TP, ; CAD, coronary artery disease. ${ }^{*}$ Refers to the characteristics of the dialysis-dependent subgroup of the study by Winther et al. [13]. ${ }^{* *}$ This study consists of 2 cohorts: (1) a retrospective analysis of the prospectively enrolled participants of the ACCURACY trial with end-stage kidney disease (testing indication: symptoms); (2) a retrospective cohort assembled from 2 medical centers meeting the criteria of end-stage kidney disease and CCTA and invasive coronary angiography within 6 months of each other (testing indication: unknown).

form more tests of heterogeneity. To compute summary statistics, we applied the random effects bivariate binomial model using a peer-reviewed, web-based app [15]. Briefly, the MetaDTA app is a web-based "point and click" interactive online application constructed using the statistical software R. The statistical approach is the random effects bivariate binomial model of Chu and Cole [16] that is mathematically identical to the hierarchical summary receiver operating characteristic (HSROC) model and the standard for summarizing across diagnostic studies $[17,18]$. We verified the primary output by validating it against the MetaDTA SAS macro published by Cochrane Methods [17].

Due to the small number of studies, we were unable to (1) assess the effect of any covariates; (2) construct an interpretable HSROC; or perform the Deeks test to assess for publication bias.

For the primary analysis, we analyzed data at the patient level ( $n=3$ studies). We did not include lio et al. [19] because patientlevel data was not reported. For secondary analyses, we restricted analysis at the patient level to dialysis-dependent patients only ( $n=3$ studies) to specifically examine whether the performance of CCTA differed in the subset of dialysis-dependent patients. For completeness' sake, we also analyzed data at the vessel level $(n=2$ studies) and presented the data in online supplement S4.

\section{Results}

\section{Study Selection}

After excluding duplicates, our systematic review retrieved 455 potentially relevant titles (Fig. 1). Four hundred forty-four records were excluded: 138 were not original re- search works; 305 were original research works but did not meet eligibility criteria. We selected 12 full-text records for further assessment, from which we excluded 6 records for reasons of duplicate publication $(n=5)$ and preliminary results of an already included study $(n=1)$. Of the 6 records that met inclusion and exclusion criteria, 2 were conference abstracts unassociated with peer-reviewed publications. We included these conference abstracts in our qualitative assessment but excluded them from the quality assessment and meta-analysis. Our final analysis, therefore, included 4 studies. Table 1 outlines their patient characteristics; Table 2 outlines their imaging characteristics.

Three studies [13,20,21] contained enough information to populate the requisite contingency table to assess diagnostic performance at the patient level. Two studies $[19,20]$ contained enough information to complete the contingency table at the vessel level. Only Park et al. [20] contained enough information for both sets of analysis.

In addition to the 4 studies, we identified 2 conference abstracts meeting our inclusion and exclusion criteria published at 2 centers in Brazil and New Zealand [22, 23] (online suppl. S3).

\section{Quality Assessment}

Table 3 summarizes the quality assessment of the results. The risk of bias was low in all domains for Winther
Cheng et al. 




Fig. 1. Flow diagram of the review process. CKD, chronic kidney disease; ESKD, end-stage kidney disease; CCTA, coronary computed tomography angiography.

Table 2. Imaging characteristics of included studies

\begin{tabular}{lllllllllll}
\hline First author [ref.], year & $\begin{array}{l}\text { Detectors } \\
\text { (rows) }\end{array}$ & $\begin{array}{l}\text { Contrast } \\
\text { volume, } \mathrm{mL}\end{array}$ & $\begin{array}{l}\text { Median } \\
\text { calcium score }\end{array}$ & Analysis level & TP & FP & $\begin{array}{c}\text { FN } \\
\text { TN }\end{array}$ & $\begin{array}{l}\text { Sensi- } \\
\text { tivity }\end{array}$ & $\begin{array}{l}\text { Spe- } \\
\text { cificity }\end{array}$ \\
\hline Iio [19], 2008 & 24 & 85 & Not done & Vessel & 25 & 7 & 4 & 29 & 0.86 & 0.81 \\
\hline Park [20], 2011 & 64 & 100 & 354 & Patient, vessel & 13 & 3 & 1 & 12 & 0.93 & 0.80 \\
\hline Jug [21], 2013 & 64 & 67 & 519 & Patient, vessel** & 22 & 2 & 0 & 7 & 1.00 & 0.78 \\
\hline Winther [13], 2015 & 128 & 95 & 137 & Patient & 28 & 40 & 2 & 68 & 0.93 & 0.63 \\
\hline $\begin{array}{l}\text { Winther [13], 2015 } \\
\text { (dialysis subgroup)* }\end{array}$ & 128 & 95 & 626 & Patient & 16 & 19 & 0 & 24 & 1.00 & 0.56 \\
\hline
\end{tabular}

We displayed all prevalences, TP, FP, FN, TN, and sensitivities and specificities at the patient level, except for Iio et al. [19] in which only vessel-level results were reported. TP, true positive; FP, false positive; FN, false negative; TN, true negative. ${ }^{*}$ Refers to the characteristics of the dialysis-dependent subgroup of the study by Winther et al. [13]. ** There was insufficient information in the manuscript to construct the 2 by 2 contingency table at the vessel level.

et al. [13]. Considerable sources of bias existed for all other 3 studies, especially pertaining to patient selection and flow and timing. In 2 studies (Iio et al. [19] and Park et al. [20]), only patients whose CCTA test results were concerning underwent invasive coronary angiography. Such a study design will naturally overestimate the sensitivity of CCTA. In Jug et al. [21], a part of the cohort came from the prospective ACCURACY trial and the rest came from a retro- 


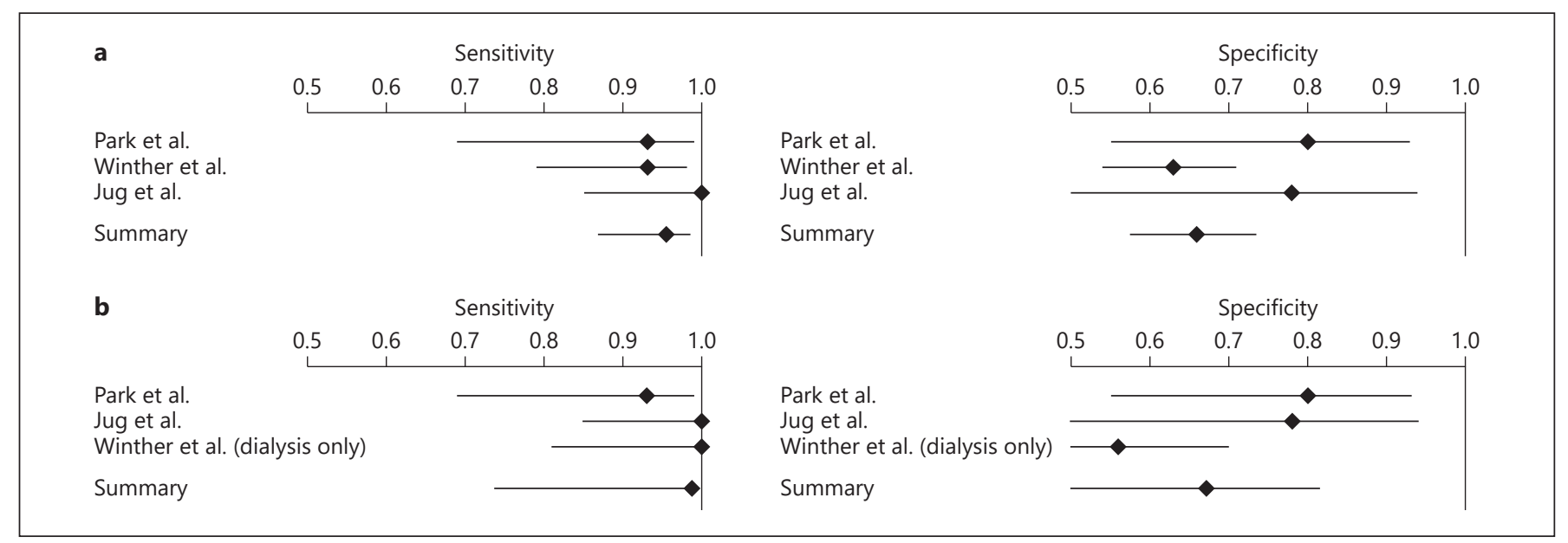

Fig. 2. Forest plot of sensitivity and specificity of computed tomography angiography compared to invasive coronary angiography in all patients $(\mathbf{a}: n=198)$ and dialysis-dependent patients $(\mathbf{b}: n=119)$.

Table 3. Assessment of methodological quality of included studies using the QUADAS-2 criteria

\begin{tabular}{|c|c|c|c|c|c|c|c|}
\hline \multirow{2}{*}{$\begin{array}{l}\text { First author [ref.], } \\
\text { year }\end{array}$} & \multicolumn{4}{|c|}{ Risk of bias } & \multicolumn{3}{|c|}{ Applicability concerns } \\
\hline & $\begin{array}{l}\text { patient } \\
\text { selection }\end{array}$ & $\begin{array}{l}\text { index } \\
\text { test }\end{array}$ & $\begin{array}{l}\text { reference } \\
\text { standard }\end{array}$ & $\begin{array}{l}\text { flow and } \\
\text { timing }\end{array}$ & $\begin{array}{l}\text { patient } \\
\text { selection }\end{array}$ & $\begin{array}{l}\text { index } \\
\text { test }\end{array}$ & $\begin{array}{l}\text { reference } \\
\text { standard }\end{array}$ \\
\hline Iio [19], 2008 & high & $?$ & low & high & low & $?$ & low \\
\hline Park [20], 2011 & high & low & $?$ & high & low & low & low \\
\hline Jug [21], 2013 & high & low & low & high & low & low & low \\
\hline Winther [13], 2015 & low & low & low & low & low & low & low \\
\hline
\end{tabular}

QUADAS-2: Quality Assessment of Studies of Diagnostic Accuracy included in Systematic Reviews-2.

spective cohort, but details of the retrospective cohort and indications for the CCTA and invasive coronary angiograms were unclear. Given the high probability that only patients with positive CCTA results underwent invasive coronary angiography, the design again will overestimate the sensitivity of CCTA. In Park et al. [20], we were unable to assess the risk of bias in the reference standard: whether the readers and adjudicators were blinded was not reported. In Iio et al. [19], we were unable to assess the applicability of the index test: it was unclear who, a cardiologist or radiologist, was responsible for interpreting the CCTA.

Of the 2 conference abstracts (online suppl. S3), both harbored considerable sources of bias in reference standard and patient selection: Rocha et al. [22] was a retrospective study and did not specify the circumstances under which CCTA and coronary angiogram were obtained; in Gleeson et al. [23], patients only underwent coronary angiogram if CCTA showed obstructive CAD. The 2 studies reported a sensitivity of $0.85-1.00$ and a specificity of $0.72-0.94$.

\section{Analysis}

In the 3 studies included in the primary analysis, sensitivity and specificity were weakly to moderately correlated $(\rho=0.40)$. Generally, a highly (negatively) correlated sensitivity and specificity of all included studies suggest that the pairs of parameters represent the same diagnostic odds ratio, and the different reported values for sensitivity and specificity are because of different cutoffs chosen by the studies [14]. The weaker correlation in our 3 studies suggests that factors other than the cutoff effect likely also contributed to the heterogeneity.

We pooled results from 3 studies with a total of 198 patients, of whom $66(33 \%)$ had at least 1 significant ste-
48

Cardiorenal Med 2021;11:44-51 DOI: $10.1159 / 000510402$
Cheng et al. 
nosis by coronary angiogram. The pooled sensitivity and specificity for CCTA were $0.96(0.87-0.99)$ and 0.66 (0.57-0.74), respectively (Fig. 2a). The diagnostic odds ratio and positive and negative likelihood ratios for CCTA were 40.6 ( -8.6 to 89.8 ), 2.8 ( 2.1 to 3.5 ), and 0.07 (0.01 to $0.15)$, respectively.

When we restricted the analysis to dialysis-dependent patients $(n=119)$, of whom $52(43 \%)$ had at least 1 significant stenosis by coronary angiogram, the pooled sensitivity and specificity for CCTA were 0.99 (0.74-1.00) and 0.67 (0.49-0.82), respectively (Fig. $2 \mathrm{~b})$. The diagnostic odds ratio and positive and negative likelihood ratios for CCTA were 166 (-388 to 719), 3.0 (1.5 to 4.6), and 0.02 (-0.04 to 0.08$)$, respectively.

\section{Discussion}

In this study, we systematically reviewed available studies assessing the diagnostic performance of CCTA in patients with advanced kidney disease. Studies from the United States and Canada demonstrate a rising use of CCTA and falling use of other noninvasive modalities over the last decade $[24,25]$. We suspect similar trends in patients with kidney disease. Whether CCTA performs as well in patients with kidney disease as it does in the general population is, therefore, an important unknown.

Our main finding is that the area remains underexplored and that future studies can benefit from (1) better study flow and patient selection and (2) consideration of dialysis vintage as a modifying factor. After an extensive and systematic literature search, we only found 4 studies addressing this problem. Aside from 1 high-quality study [13], the other 3 studies have significant sources of bias in patient selection and study flow, mostly related to the nonuniform assignment of invasive coronary angiography based on CCTA results. These study design factors all contribute to the heterogeneity among studies. There is insufficient data on dialysis vintage (only 2 studies reported this) to assess the effect of dialysis vintage on CCTA's diagnosis performance. Given the known association with coronary calcification and dialysis vintage [26], future studies in the area should both include dialysis-dependent patients and specifically stratify them by dialysis vintage.

CCTA appears to be sensitive for obstructive CAD in patients with advanced CKD, consistent with findings in the general population [3]. This finding is mostly driven by the one high-quality study included [13]. The result is unaltered when we restrict analysis to only dialysis-de-

Coronary Computed Tomography

Angiography in CKD pendent patients. The specificity of CCTA, around $0.66-$ 0.67 , is considerably lower than in the general population [3] and what has been reported for dobutamine stress echocardiogram (0.89) and myocardial perfusion scintigraphy (0.77) in the CKD population [10]. Mechanistically, the low specificity is unsurprising, given the high coronary calcification burden in patients with CKD [27], which may complicate imaging interpretation and increase the likelihood of false positives [20]. Indeed, the studies we included reported a high coronary calcium score (median of 354-626 across studies, where $\geq 400$ typically denotes high risk of disease [28]). The combination of high sensitivity and low specificity suggests that CCTA may be a good first-line or "rule-out" screening test. Combining CCTA with a second imaging modality with higher specificity, as Winther et al. [13, 29] have proposed, may be a reasonable approach to screening patients with advanced kidney disease. The chief advantage of a two-tiered approach is the possible avoidance of invasive testing, i.e., coronary angiogram, with its associated complications and patient discomfort. The main drawback, however, is increased cost of an additional test as well as excess contrast and radiation exposure. CT angiography-derived fraction flow reserve is another promising application of CCTA. It can potentially improve the specificity of CCTA by noninvasively assessing whether a coronary stenosis is hemodynamically significant on CCTA [30-32]. Other new techniques include the contrast-free coronary angiography [33] which may be particularly relevant for pre-dialysis patients in whom the risk of contrast-induced nephropathy is a concern.

Of the 4 studies included, 3 were limited to dialysisdependent patients, and contrast-induced nephropathy was, therefore, not studied. In the study by Winther et al. [13], which included pre-dialysis patients, postcontrast acute kidney injury occurred in $13 \%$ of patients after CCTA, was reversible in all these patients, and did not increase the risk of accelerated CKD progression [34]. De Bie et al. [35] reported the outcomes of CCTA in a cohort of 70 dialysis-dependent patients; they reported no apparent decrease in residual kidney function in any patient. Taken together, CCTA appears to be safe in patients with advanced CKD, although safety data is only available for patients selected for research studies and generalizability is, therefore, limited.

Limitations of our study include the small number of studies, limiting our ability to examine the effects of covariates. We must caution also that the studies appear to be highly heterogeneous, especially pertaining to patient selection and study design, so any interpretation of the 
pooled results must be measured. The pooled results are driven by 1 high-quality study [13]. In the high-quality study [13], overall CAD prevalence and coronary calcium scores were the lowest. In the other studies, study design biases the results toward higher sensitivity. The results of our primary analysis, therefore, may not be applicable to patients with longer dialysis duration and higher CAD prevalence and coronary calcification burden.

In summary, we hereby present findings from our systematic review and meta-analysis of studies examining the purpose of CCTA in patients with advanced kidney disease. Our findings highlight the knowledge gaps in the field, especially the small number of studies and lack of information on the effects of dialysis vintage on CCTA performance. Allowing for the limited number, we confirm the high sensitivity of CCTA but discover the lower specificity of CCTA in our study population compared to the general population. If used in the $\mathrm{CKD}$ and end-stage kidney disease population, CCTA needs to be coupled with a second test with higher specificity.

\section{Acknowledgement}

We acknowledge the assistance of Connie $\mathrm{H}$. Wong, the librarian at Stanford School of Medicine Lane Library, in designing the search term and performing the search.

\section{Statement of Ethics}

This research is based on published data and, thus, exempt from requiring ethics approval.

\section{Conflict of Interest Statement}

W.F.F. reports receiving a research grant from Abbott and Medtronic, and holding minor stock options with HeartFlow. All other authors declare no conflicts of interest.

\section{Funding Sources}

Research reported here was supported by the American Heart Association (AHA) under award number 19CDA34490021 (X.S.C.). The AHA had no role in the preparation of the data, preparation of the manuscript, or decision to publish.

\section{Author Contributions}

Study design: X.S.C., D.F., J.C.T., W.F.F.

Data acquisition: X.S.C., S.M., V.T., S.W.

Results interpretation: X.S.C., S.M., V.T., D.M., D.F., J.C.T., W.F.F.

Manuscript drafting and revision: X.S.C., S.M., V.T., D.M., S.W., D.F., J.C.T., W.F.F.

\section{References}

1 Al-Mallah MH, Aljizeeri A, Villines TC, Srichai MB, Alsaileek A. Cardiac computed tomography in current cardiology guidelines. J Cardiovasc Comput Tomogr. 2015 Nov-Dec; 9(6):514-23.

2 Knuuti J, Wijns W, Saraste A, Capodanno D, Barbato E, Funck-Brentano C, et al.; ESC Scientific Document Group. 2019 ESC Guidelines for the diagnosis and management of chronic coronary syndromes. Eur Heart J. 2020 Jan;41(3):407-77.

3 Miller JM, Rochitte CE, Dewey M, Arbab-Zadeh A, Niinuma H, Gottlieb I, et al. Diagnostic performance of coronary angiography by 64 row CT. N Engl J Med. 2008 Nov;359(22): 2324-36.

4 Stefanini GG, Windecker S. Can coronary computed tomography angiography replace invasive angiography? Coronary computed tomography angiography cannot replace invasive angiography. Circulation. 2015 Jan; 131(4):418-25.

5 Raggi P, Boulay A, Chasan-Taber S, Amin N, Dillon M, Burke SK, et al. Cardiac calcification in adult hemodialysis patients. A link between end-stage renal disease and cardiovascular disease? J Am Coll Cardiol. 2002 Feb; 39(4):695-701.
6 Sharples EJ, Pereira D, Summers S, Cunningham J, Rubens M, Goldsmith D, et al. Coronary artery calcification measured with electron-beam computerized tomography correlates poorly with coronary artery angiography in dialysis patients. Am J Kidney Dis. 2004 Feb;43(2):313-9.

7 Park MJ, Jung JI, Choi YS, Ann SH, Youn HJ, Jeon GN, et al. Coronary CT angiography in patients with high calcium score: evaluation of plaque characteristics and diagnostic accuracy. Int J Cardiovasc Imaging. 2011 Dec; 27(S1 Suppl 1):43-51.

8 Shroff GR, Chang TI. Risk Stratification and Treatment of Coronary Disease in Chronic Kidney Disease and End-Stage Kidney Disease. Semin Nephrol. 2018 Nov;38(6):582-99.

9 Hart A, Weir MR, Kasiske BL. Cardiovascular risk assessment in kidney transplantation. Kidney Int. 2015 Mar;87(3):527-34.

10 Wang LW, Fahim MA, Hayen A, Mitchell RL, Baines L, Lord S, et al. Cardiac testing for coronary artery disease in potential kidney transplant recipients. Cochrane Database Syst Rev. 2011 Dec;12(12):CD008691.
11 Moher D, Liberati A, Tetzlaff J, Altman DG; PRISMA Group. Preferred reporting items for systematic reviews and meta-analyses: the PRISMA statement. Ann Intern Med. 2009 Aug;151(4):264-9.

12 Whiting PF, Rutjes AW, Westwood ME, Mallett S, Deeks JJ, Reitsma JB, et al.; QUADAS-2 Group. QUADAS-2: a revised tool for the quality assessment of diagnostic accuracy studies. Ann Intern Med. 2011 Oct;155(8): 529-36.

13 Winther S, Svensson M, Jørgensen HS, Bouchelouche K, Gormsen LC, Pedersen BB, et al. Diagnostic performance of coronary $\mathrm{CT}$ angiography and myocardial perfusion imaging in kidney transplantation candidates. JACC Cardiovasc Imaging. 2015 May;8(5):553-62.

14 Devillé WL, Buntinx F, Bouter LM, Montori VM, de Vet HC, van der Windt DA, et al. Conducting systematic reviews of diagnostic studies: didactic guidelines. BMC Med Res Methodol. 2002 Jul;2(9):9.

15 Freeman SC, Kerby CR, Patel A, Cooper NJ, Quinn T, Sutton AJ. Development of an interactive web-based tool to conduct and interrogate meta-analysis of diagnostic test accuracy studies: MetaDTA. BMC Med Res Methodol. 2019 Apr;19(1):81. 
$16 \mathrm{Chu} \mathrm{H}$, Cole SR. Bivariate meta-analysis of sensitivity and specificity with sparse data: a generalized linear mixed model approach. J Clin Epidemiol. 2006 Dec;59(12):1331-2.

17 Cochrane Methods. Software for meta-analysis of DTA Studies. Published online 2012 [cited 2019 Sep 9]. Available from: https:// methods.cochrane.org/sdt/software-metaanalysis-dta-studies

18 Lee J, Kim KW, Choi SH, Huh J, Park SH. Systematic Review and Meta-Analysis of Studies Evaluating Diagnostic Test Accuracy: A Practical Review for Clinical Researchers-Part II. Statistical Methods of Meta-Analysis. Korean J Radiol. 2015 Nov-Dec;16(6):1188-96.

19 Iio K, Nagasawa Y, Kimura T, Yamasaki K, Takeda Y, Hamano T, et al. Assessment of coronary stenosis by a 16-slice MDCT scanner in asymptomatic diabetic patients starting dialysis therapy. Nephron Clin Pract. 2008; 109(2):c72-9.

20 Park MY, Choi SJ, Kim JK, Hwang SD, Suh J, Seo HS, et al. Use of multidetector computed tomography for evaluating coronary artery disease in patients undergoing dialysis. $\mathrm{Ne}-$ phrology (Carlton). 2011 Mar;16(3):285-9.

21 Jug B, Papazian J, Gupta M, Bhatia H, Derakhshani A, Koplik S, et al. Diagnostic performance of computed tomographic coronary angiography in patients with end-stage renal disease. Coron Artery Dis. 2013 Mar;24(2): $135-41$.

22 Rocha R, De Lima J, Rosario Neto M, et al. Coronary angiography by MDCT in endstage renal failure patients: diagnostic and prognostic value. Echocardiography. 2012; 29(2):261-2.

23 Gleeson S, De Zoysa J, To A. Computed tomography coronary angiography use in end stage renal failure. Nephrology (Carlton). 2017;22:88
24 Morris JR, Bellolio MF, Sangaralingham LR, Schilz SR, Shah ND, Goyal DG, et al. Comparative trends and downstream outcomes of coronary computed tomography angiography and cardiac stress testing in emergency department patients with chest pain: an administrative claims analysis. Acad Emerg Med. 2016 Sep;23(9):1022-30.

25 Roifman I, Wijeysundera HC, Austin PC, Maclagan LC, Rezai MR, Wright GA, et al. Temporal trends in the utilization of noninvasive diagnostic tests for coronary artery disease in Ontario between 2008 and 2014: A population-based study. Can J Cardiol. 2017 Feb;33(2):279-82.

26 Nishizawa Y, Mizuiri S, Yorioka N, Hamada C, Tomino Y. Determinants of coronary artery calcification in maintenance hemodialysis patients. J Artif Organs. 2015 Sep;18(3): 251-6.

27 Bashir A, Moody WE, Edwards NC, Ferro CJ Townend JN, Steeds RP. Coronary artery calcium assessment in CKD: utility in cardiovascular disease risk assessment and treatment? Am J Kidney Dis. 2015 Jun;65(6):937-48.

28 Blaha MJ, Mortensen MB, Kianoush S, TotaMaharaj R, Cainzos-Achirica M. Coronary artery calcium scoring: is it time for a change in methodology? JACC Cardiovasc Imaging. 2017 Aug;10(8):923-37.

29 Winther S, Bøttcher M, Jørgensen HS, Bouchelouche K, Gormsen LC, Oczachowska-Kulik AE, et al. Coronary calcium score may replace cardiovascular risk factors as primary risk stratification tool before kidney transplantation. Transplantation. 2016 Oct; 100(10):2177-87.
30 Zhuang B, Wang S, Zhao S, Lu M. Computed tomography angiography-derived fractional flow reserve (CT-FFR) for the detection of myocardial ischemia with invasive fractional flow reserve as reference: systematic review and meta-analysis. Eur Radiol. 2020 Feb; 30(2):712-25.

31 Mastrodicasa D, Albrecht MH, Schoepf UJ, Varga-Szemes A, Jacobs BE, Gassenmaier S, et al. Artificial intelligence machine learningbased coronary CT fractional flow reserve (CT-FFRML): impact of iterative and filtered back projection reconstruction techniques. J Cardiovasc Comput Tomogr. 2019 Nov - Dec; 13(6):331-5.

32 Tesche C, De Cecco CN, Baumann S, Renker M, McLaurin TW, Duguay TM, et al. Coronary CT angiography-derived fractional flow reserve: machine learning algorithm versus computational fluid dynamics modeling. Radiology. 2018 Jul;288(1):64-72.

33 Ali ZA, Karimi Galougahi K, Nazif T, Maehara A, Hardy MA, Cohen DJ, et al. Imagingand physiology-guided percutaneous coronary intervention without contrast administration in advanced renal failure: a feasibility, safety, and outcome study. Eur Heart J. 2016 Oct;37(40):3090-5.

34 Winther S, Svensson M, Jørgensen HS, Birn $\mathrm{H}$, Bøtker HE, Ivarsen P, et al. Repeated contrast administration is associated with low risk of postcontrast acute kidney injury and long-term complications in patients with severe chronic kidney disease. Am J Transplant. 2016 Mar;16(3):897-907.

35 de Bie MK, Buiten MS, Gaasbeek A, Boogers MJ, Roos CJ, Schuijf JD, et al. CT coronary angiography is feasible for the assessment of coronary artery disease in chronic dialysis patients, despite high average calcium scores. PLoS One. 2013 Jul;8(7):e67936. 